\title{
GUIA PRÁTICO PARA CONHECIMENTO E IDENTIFICAÇĀO DAS TAINHAS E PARATIS (PISCES, MUGILIDAE) DO LITORAL BRASILEIRO
}

NAERCIO AQUINO MENEZES

\section{ABSTRACT}

Although mullets from the Brazilian coast have been commercially exploited for a long time and used in fish culture experiments more recently, data for accurate identification of species are not available in the Brazilian literature.

This guide was planned to provide information for the identification of all the species found along the Brazilian coast, based on inspection of easily recognizable morphological features. A key to species and data on their distribution, fishery, biology and fish culture in Brazil are presented.

\section{INTRODUÇAO}

Os peixes da família Mugilidae têm ampla distribuição, ocorrendo em águas tropicais e subtropicais de todo o mundo, principalmente na região costeira estuarina. São explorados comercialmente em todas as regiões onde ocorrem, constituindo assim uma parte importante da alimentação humana.

No Brasil, são conhecidos vulgarmente como tainhas e paratis na região Sudeste e Sul e como tainhas e curimãs no Norte e Nordeste. Embora pescados tradicionalmente há muito tempo no litoral brasileiro e utilizados mais recentemente em projetos de piscicultura e criação em viveiros, não existe trabalho algum na literatura brasileira que possibilite a identificação adequada das espécies. É comum, em trabalhos de cultivo e criação, utilizar-se apenas o nomè do gênero (Bertoletti, 1976; Silva, 1976). Por serem muito parecidas, duas ou mais espécies de Mugil podem ser facilmente confundidas e tratadas como se representassem uma só. A importância da identificação correta da espécie ou espécies em questão para confiabilidade dos dados apresentados é óbvia.

Apesar de muito semelhantes entre si, as espécies de Mugil do litoral brasileiro podem ser identificadas com relativa facilidade, desde que alguns caracteres da morfologia externa sejam observados atentamente. Este guia tem por objetivo salientar estas características e, por meio de ilustrações e uma chave de identificação, permitir um reconhecimento seguro a nível de espécie.

\section{TAXONOMIA E DISTRIBUIÇĀO}

Embora ocorram pelo menos sete espécies de mugilídeos nas costas do Brasil, apenas três têm sido mais exploradas comercialmente ou em projetos de cultivo: Mugil liza, Mugil platanus e $M$. curema. Por atingir um tamanho maior que $M$. curema, as outras duas espécies são mais procuradas; alcançam um preço maior no mercado e são também mais utilizadas em piscicultura. $M$. liza é a curimã do Nordeste e $M$. platanus a tainha do Sudeste e Sul do Brasil, M. curema é chamada de parati no Sudeste e Sul e de tainha no Nordeste. Das outras quatro espécies, $M$. gaimardianus e $M$. curvidens são menos comuns e podem ser mesmo consideradas raras e $M$. incilis e $M$. trichodon são relativamente abundantes apenas no Norte e Nordeste, onde são também utilizadas em viveiros e em projetos de criação, porém em menor escala que $M$. curema.

Para a identificação das espécies, os caracteres externos mais utilizados são o padrão de colorido, o número de séries laterais de escamas, o grau de

Museu de Zoologia, Universidade de Säo Paulo. 
escamação da segunda nadadeira dorsal e da nadadeira anal e o número de raios da nadadeira anal. Na Figura 1 é possivel reconhecer as principais estruturas utilizadas no reconhecimento das espécies. Com relação ao padrão de colorido, existe uma diferença nítida entre $M$. liza e $M$. platanus que possuem estrias escuras longitudinais evidentes alternadas com estrias claras e as demais espécies que possuem o corpo prateado sem estrias escuras longitudinais evidentes. A contagem de séries laterais de escamas refere-se ao número de séries dispostas inclinadamente, iniciando-se pela série que se localiza imediatamente atrás da margem posterior do opérculo, terminando com a série localizada na base da nadadeira caudal; o comprimento mencionado no texto e figuras refere-se sempre ao comprimento total (veja Fig. 1). Os dados (contagens, medidas, etc.) das espécies foram obtidos de exemplares depositados na coleção ictiológica do Museu de Zoologia da Universidade de São Paulo (MZUSP).

A chave para identificação das espécies, abaixo, é aplicável apenas a indivíduos maiores que $5 \mathrm{~cm}$. Exemplares com tamanho inferior têm um número diferente de espinhos e raios na nadadeira anal, uma vez que o terceiro "raio" só vai se transformar em "espinho" em estágios mais adiantados de desenvolvimento.

\section{CHAVE PARA AS ESPECIES DO GENERO MUGIL DO LITORAL BRASILEIRO}

1. Segunda nadadeira dorsal e nadadeira anal quase totalmente recobertas

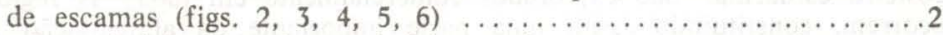

Segunda nadadeira dorsal e nadadeira anal com escamas restritas apenas

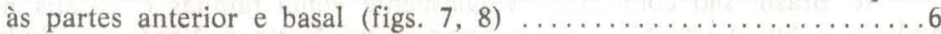

2. Nadadeira anal com 3 espinhos e 8 raios $\ldots \ldots \ldots \ldots \ldots \ldots \ldots \ldots \ldots$

Nadadeira anal com 3 espinhos e 9 raios ..................

3. Dentes com a ponta muito curva, formando um ângulo quase reto (Fig. $2 \mathrm{~A})$, quase imperceptíveis a olho nu .................. curvidens

Dentes normais, sem ponta acentuadamente curva, visíveis a olho nu mesmo em exemplares relativamente pequenos ............ trichodon

4. 41 a 44 séries laterais de escamas; origem da primeira nadadeira dorsal mais próxima da ponta do focinho do que da base da nadadeira

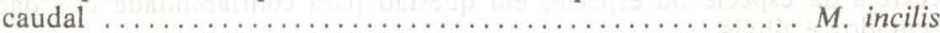

35 a 40 séries laterais de escamas; origem da primeira nadadeira dorsal equidistante da ponta do focinho e da base da nadadeira caudal, ou mais próxima da base da nadadeira caudal do que da ponta do

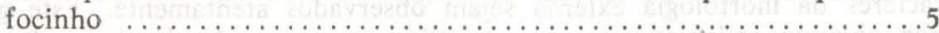

5. Ponta da nadadeira peitoral não alcançando a vertical traçada a partir da origem da primeira nadadeira dorsal (Fig. 5); 36 a 40 (geralmente 38 ou 39) séries laterais de escamas; escamas ciclóides nos jovens (Fig. 5B), fracamente ctenóides nos exemplares adultos (Fig. 5A)

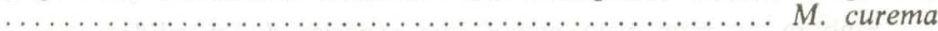

Ponta da nadadeira peitoral alcançando ou ultrapassando a vertical traçada a partir da origem da primeira nadadeira dorsal (Fig. 6); 35 a 38 (geralmente 36 ou 37) séries laterais de escamas; escamas ctenóides nos jovens (Fig. 6B), fracamente ctenóides em exemplares adultos (Fig. 6A) ........................... gaimardianus

6. 29 a 34 séries laterais de escamas ........................ M. liza 34 a 40 séries laterais de escamas ...................... platanus

Mugil curvidens Valenciennes, 1836

(Fig. 2)

Pode ser facilmente reconhecida pela característica peculiar da dentição. Os dentes têm a ponta curva para dentro da boca, formando um ângulo quase reto em relação ao corpo do dente (Fig. 2A). Nenhum outro mugilídeo do Brasil apresenta esta característica.. E rara e pouco conhecida no litoral brasileiro, onde ao que tudo indica só aparece esporadicamente. $\mathrm{Na}$ coleção 
ictiológica do Museu de Zoologia da USP existe apenas um exemplar coletado na Praia dos Anjos, Cabo Frio, RJ, que mede $27 \mathrm{~cm}$ e apresenta as seguintes características adicionais: 36 séries laterais de escamas, origem da primeira nadadeira dorsal ligeiramente mais próxima da ponta do focinho do que da base da nadadeira caudal e segunda nadadeira dorsal e anal quase totalmente recobertas de escamas.

Ocorre no Atlântico Oriental (Costas da Âfrica) e no Atlântico Ocidental, estendendo-se neste último das Antilhas ao Rio de Janeiro.

\section{Mugil trichodon Poey, 1876}

(Fig. 3)

Muito comum no Nordeste, onde é conhecida como tainha, mas não encontrada no litoral Sudeste e Sul. Diferencia-se de todas as demais espécies porque apresenta os dentes maiores, facilmente visíveis a olho nu. Dentre as espécies que possuem a segunda nadadeira dorsal e anal densamente cobertas de escamas, assemelha-se mais a $M$. curvidens com relação ao número de elementos da nadadeira anal (ambas possuem 3 espinhos e 8 raios), mas não possui os dentes em ponta acentuadamente curva. A origem da primeira nadadeira dorsal é equidistante da ponta do focinho e da base da nadadeira caudal. O número de séries laterais de escamas varia entre 30 e 36 , sendo mais comuns os valores entre 33 e 35 .

O colorido geral é prateado, sendo a parte dorsal mais escura. As nada. deiras pélvicas e a anal são amareladas e as demais claras, com alguma pigmentação escura esparsa; a caudal tem a margem escura e existe na base da peitoral uma mancha escura.

Distribui-se da Flórida, Estados Unidos, até o nordeste do Brasil. Não existem dados sobre o seu aproveitamento em projetos de piscicultura.

\section{Mugil incilis Handock, 1830}

(Fig. 4)

Conhecida também como tainha no Norte e Nordeste e como parati no Sudeste do Brasil. Pode ser separada das outras duas espécies que também possuem 3 espinhos e 9 raios na nadadeira anal e segunda nadadeira dorsal e anal quase totalmente recobertas de escamas, porque tem maior número de séries laterais de escamas e a origem da primeira nadadeira dorsal em posição mais anterior (vide chave).

O corpo é prateado, um pouco mais escuro superiormente. As nadadeiras são amareladas com alguma pigmentação escura e a peitoral é um pouco mais escura no lado interno superior.

No Atlântico Ocidental distribui-se do Caribe e América Central até o Sudeste do Brasil. Embora citada na literatura para o leste do Brasil (Fowler, 1941), aparentemente é uma espécie rara nesta região, sendo mais comum no Nordeste e principalmente no litoral dos estados do Pará e Maranhão. Invade a água doce, sendo às vezes encontrada bem acima das bocas dos rios.

Alcança cerca de $40 \mathrm{~cm}$ de comprimento e aparece com relativa freqüência no mercado de Belém, PA. No litoral do estado do Rio Grande do Norte não foi encontrada em viveiros, tendo sido coletada para estudos de biometria com arrastōes de praia (Soares, 1971).

\section{Mugil curema Valenciennes, 1836}

(Fig. 5)

E, talvez, o mugilídeo mais comum do litoral brasileiro. Popularmente denominada de tainha no Norte e Nordeste e de parati no Sudeste e Sul, possui uma semelhança muito grande com $M$. gaimardianus da qual difere pelas características mencionadas na chave para identificação das espécies e por não apresentar, em vida, o olho característicamente avermelhado daquela espécie. 
O colorido do corpo é prateado, mais escuro na parte superior. As nadadeiras são amareladas; a segunda dorsal tem a ponta enegreecida e a caudal e a peitoral apresentam pigmentação escura esparsa; a peitoral tem uma mancha mais escura na sua base, mais evidente no lado interno da nadadeira.

Ocorre em ambos os lados do Atlântico e também no Pacífico leste. No Atlântico Ocidental, estende-se da Nova Inglaterra, Estados Unidos, até o Sul do Brasil.

Aparece no mercado, mas não tem tanto valor comercial como as espécies que atingem maior porte. Alcança no máximo cerca de $45 \mathrm{~cm}$ de comprimento, sendo entretanto comuns tamanhos em torno de $30 \mathrm{~cm}$.

$M$. curema vive em grandes cardumes e, como as outras espécies de mugilídeos, são particularmente abundantes em áreas estuarinas. Embora não existam dados precisos sobre locais de desova no litoral brasileiro, trabalhos sobre a mesma espécie em outras áreas (Rivas, 1980) indicam que ela desova em alto mar. Depois de alcançar mobilidade suficiente para nadar ativamente os pequenos indivíduos locomovem-se para áreas estuarinas, penetrando em rios e lagoas costeiras adjacentes à procura de alimento. Aí permanecem por certo tempo e, quando atingem a maturidade sexual, saem novamente para desovar. Dados sobre reprodução em áreas estuarinas de Pernambuco são mencionados por Couto \& Nascimento (1978).

No Rio Grande do Norte, Alagoas e especialmente em Pernambuco, tem sido cultivada em viveiros e gaiolas em áreas estuarinas (Silva, 1976, 1983; Costa \& Rocha, 1978).

Mugil gaimardianus Desmarest, 1831

(Fig. 6)

Tem sido confundida com $M$. curema, com a qual se assemelha bastante. Em vida pode ser diferenciada porque possui o olho avermelhado, sendo por esta razão conhecida no Nordeste como tainha-olho-de-fogo e no Sudeste e Sul como parati-olho-de-fogo. Exemplares jovens de $M$. gaimardianus podem ser reconhecidos com facilidade porque possuem escamas ctenóides bem evidentes (Fig. 6B), enquanto exemplares jovens de $M$. curema possuem escamas ciclóides (Fig. 5B). Exemplares adultos de ambas as espécies podem ser separados com base no número médio de séries laterais de escamas e na extensão da nadadeira peitoral em relação à origem da primeira nadadeira dorsal (vide chave).

Alcança o mesmo tamanho e tem o colorido do corpo semelhante a M. curema.

Ocorre da Flórida, Estados Unidos e Antilhas até o sul do Brasil. Embora tenha uma ampla distribuição em todo o litoral brasileiro, é muito menos comum que $M$. curema. Na Região Sul foi erroneamente denominada de Mugil hospes, espécie restrita às costas do México, no Oceano Pacífico.

\section{Mugil liza Valenciennes, 1836}

(Fig. 7)

O padrão de colorido, caracterizado pela presença de estrias escuras longitudinais alternadas com estrias claras, e a ausência quase total de escamas nas nadadeiras anal e segunda dorsal, separam esta espécie e $M$. platanus de todas as demais espécies do gênero Mugil do litoral brasileiro. O menor número de séries laterais de escamas (29 a 34) e a ocorrência em uma área geográfica distinta (norte e nordeste até o Rio de Janeiro) separam M. liza de $M$. platanus com segurança.

$\mathrm{Na}$ literatura muitas vezes aparece com o nome de Mugil brasiliensis, considerado impróprio por Trewawas (1950) que sugeriu sua supressão.

O corpo apresenta um colorido escuro superiormente, prateado lateral e inferiormente e percorrido por estrias longitudinais escuras aproximadamente paralelas que passam pelo centro das escamas. As nadadeiras pélvicas são amareladas e as demais possuem pigmentos escuros esparsos, principalmente 
a segunda dorsal e a caudal. $\mathrm{Na}$ base da nadadeira peitoral existe uma mancha negra.

Distribui-se do Sul da Flórida, Estados Unidos, Bermudas e Caribe até - Rio de Janeiro. Substituída na região Sudeste e Sul por M. platanus.

A curimã do Norte e Nordeste ou tainha do litoral leste do Brasil é um peixe que alcança de 1 metro de comprimento e $8 \mathrm{~kg}$ de peso. $\mathrm{Na}$ região de Cabo Frio, RJ, aparecem grandes cardumes entre abril e setembro, época em que são capturadas aos milhares por pescadores locais; durante 1978, 1979 e 1980 foi capturado um total de 146 toneladas (Benetti \& Fagundes Netto, 1981). Nesta mesma região foram realizadas com sucesso experiências de desova induzida por hipofização, fertilização, eclosão dos ovos e alevinagem, a partir da captura de reprodutores de $M$. liza em ambiente natural (Benetti \& Fagundes Netto, 1980).

Mugil platanus Günther, 1880

(Fig. 8)

A tainha do Sudeste e Sul do Brasil difere de $M$. liza por ter mais que 34 escamas em séries laterais ( 34 a 40 , mais comumente 36 ou 37). O padrão de colorido é idêntico ao de $M$. liza.

É conhecida apenas no Atlântico Sul Ocidental, desde o Rio de Janeirc até a Argentina. É relativamente rara no limite norte de sua distribuição.

$M$. platanus, como $M$. liza, tem seu ciclo de vida intimamente relacionado a regiōes estuarinas, que constituem criadouro natural dessas espécies. Alcança $1 \mathrm{~m}$ de comprimento e $6 \mathrm{~kg}$ de peso. As grandes áreas lagunares do Sudeste e Sul do Brasil, como por exemplo a Lagoa dos Patos no Rio Grande do Sul, são procuradas por $M$. platanus, que aí se desenvolvem durante um certo período até atingirem a maturação das gônadas. Embora os dados sobre - local de desova sejam contraditórios, havendo mesmo referências sobre desova em água doce (Carvalho, 1941; Ihering, 1940; Ribeiro, 1915), é provável que $M$. platanus desove em alto mar, como as espécies de tainha em geral. Estudos atualmente em desenvolvimento no Departamento de Oceanografia da Fundação Universidade de Rio Grande, RS, poderão esclarecer definitivamente o problema.

A tainha tem sido objeto de vários estudos na Região Sul principalmente nos estados de Santa Catarina e Rio Grande do Sul. Na região estuarina de Tramandaí, RS, durante 1977 e 1978 M. platanus (referida como M. liza) foi capturada em $76 \%$ dos lances de pesca efetuados, tendo sido considerada mais abundante no outono (Silva, 1982). Na Lagoa dos Patos a tainha foi a espécie dominante nos arrastos de praia no estuário e a segunda em abundância na região costeira, tendo constituído respectivamente 31,2 e 24,96\% de todos os peixes coletados (Chao et al., 1982).

Aproveitando sua ocorrência natural na região denominada Saco do Jus. tino em Rio Grande, RS, a tainha foi cultivada durante algum tempo com a utilização de cercos (Bertoletti, 1976). Infelizmente os dados de captura por ocasião da despesca não podem ser avaliados, uma vez que não foi feita uma identificação a nível de espécie, sendo impossível saber se no ambiente onde desenvolveu-se o projeto havia apenas $M$. platanus.

\section{AGRADECIMENTOS}

Os Drs. José Lima de Figueiredo e Nelson Papavero, do Museu de Zoologia da Universidade São Paulo, leram o manuscrito e ofereceram valiosas sugestões para o seu aprimoramento. Os desenhos são de autoria de Nelson F. Gomes.

\section{REFERENCIAS}

Benetti, D. D. \& E. B. Fagundes Netto, 1980. Considerações sobre desova e alevinagem da tainha (Mugil liza Valenciennes, 1836) em laboratório. Inst. Pesq. Mar. Rio de J, Publ. 135: 1-26. 
Benetti, D. D. \& E. B. Fagundes Netto, 1981. Ocorrência, captura e mercado da tainha (Mugil liza Valenciennes, 1836) na região de Arraial do Cabo, RJ $\left(22^{\circ} 55^{\prime} \mathrm{S}, 42^{\circ} 05^{\prime} \mathrm{W}\right)$ Ibid. 138: 1-17.

Bertoletti, J. J., 1976. Projeto Tainha (Rio Grande - RS). Dados preliminares. Com. Mus. Ci. PUCRGS P. Alegre 12: 1-20.

Bertoletti, J. J., s.d. Projeto Tainha (Fazenda de Pescados de Rio Grande - RS). Resultados da despesca. Secret. Agric. Est. Rio Grande do Sul, 155 pp.

Carvalho, J. de P., 1941. Nota preliminar sobre a fauna ictiológica do litoral do Sul do Estado de São Paulo, Bolm Ind. anim., S Paulo 4 (3/4): 27-81.

Chao, L.N., L.E. Pereira, J.P. Vieira, M.A. Bemvenuti \& L.P.R. Cunha, 1982. Relação preliminar dos peixes estuarinos e marinhos da Lagoa dos Patos e região costeira adjacente, Rio Grande do Sul, Brasil. Atlântico, Rio Grande 5: 67-75.

Costa, F. J. C. \& I. P. Rocha, 1978. Aspectos quantitativos do cultivo da tainha (Mugil curema Valenciennes, 1836) (Itamaracá-Pernambuco). I Simp. Bras. Aquic. Recife (Julho 1978): 114.

Couto, L. M. M. R. \& I. V. Nascimento, 1978. Reprodução da tainha (Mugil curema) em águas estuarinas de Pernambuco, Brasil. Ibid.: 94-95.

Fowler, H. W., 1941. A list of the fishes known from the coast of Brasil. Arqos Zool. S. Paulo 3(6): 115-184.

Ihering, R. v., 1940. Dicionário dos Animais do Brasil. São Paulo, Diretoria de Publicidade Agrícola, 898 pp.

Ribeiro, A. de M., 1915. Fauna Brasiliense V. (Eleutherobranchios Aspirophoros) Physoclisti. Archos Mus. nac. R. de J. 17: 679 pp.

Rivas, L. R., 1980. Synopsis of knowledge on the taxonomy, biology, distribution and fishery of the Gulf of Mexico mullets (Pisces: Mugilidae), pp. 34-53, in M. Flandorfer \& L. Skupien, eds., "Proc." Work. Pot. Fish. Res. Northern Gulf of Mexico.

Silva, C. P. da, 1982. Ocorrência, distribuição e abundấncia de peixes na região estuarina de Tramandaí, Rio Grande do Sul. Atlântico, Rio Grande 5: $49-66$.

Silva, J. E. da, 1976. Possibilidades de desenvolvimento da piscicultura estuarina na costa nordeste do Brasil, pp. 241-245 in J. I. Vargas, C. G. C. Loureiro \& R. M. Andrade, eds., An. I Enc. nac. Limnol. Pisc. e Pesca Cont. (Belo Horizonte, Minas Gerais).

Silva, J. E. da, 1983. O uso de redes, viveiros e gaiolas na piscicultura. Res. $X$ Congr. bras. Zool. (Belo Horizonte, Minas Gerais): p. 290.

Trewawas, E., 1950. The status of the American mullets, Mugil brasiliensis and M. curema. Copeia 1950 (2):149. 
Vol. 2(1), 1983

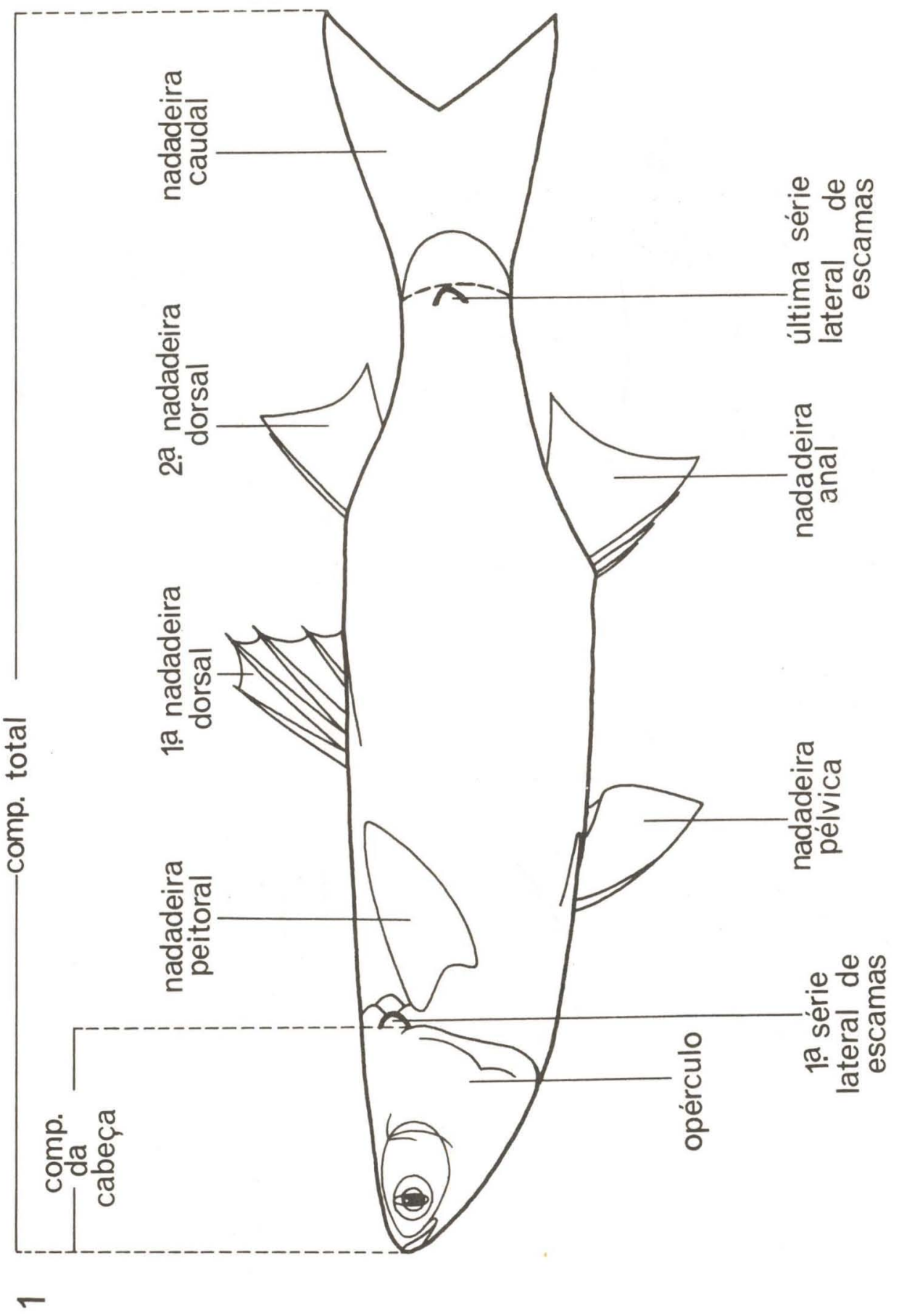

Fig. 1 - Nome das principais estruturas morfológicas de um mugilídeo. 

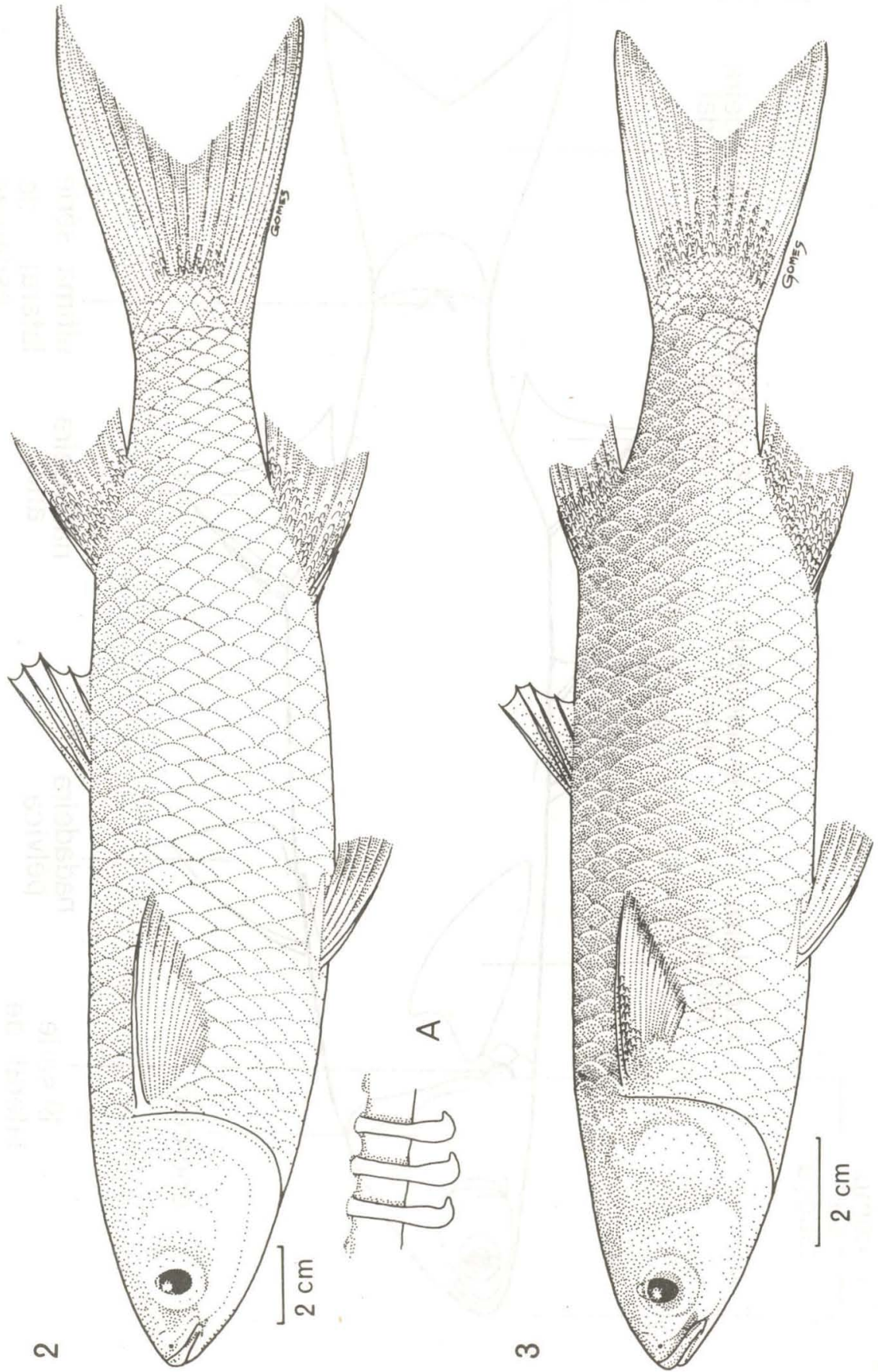

Fig. 2 - Mugil curvidens, 35,0 cm; A - parte da dentição da arcada bucal superior. Fig. 3 - Mugil trichodon, $24,5 \mathrm{~cm}$. 


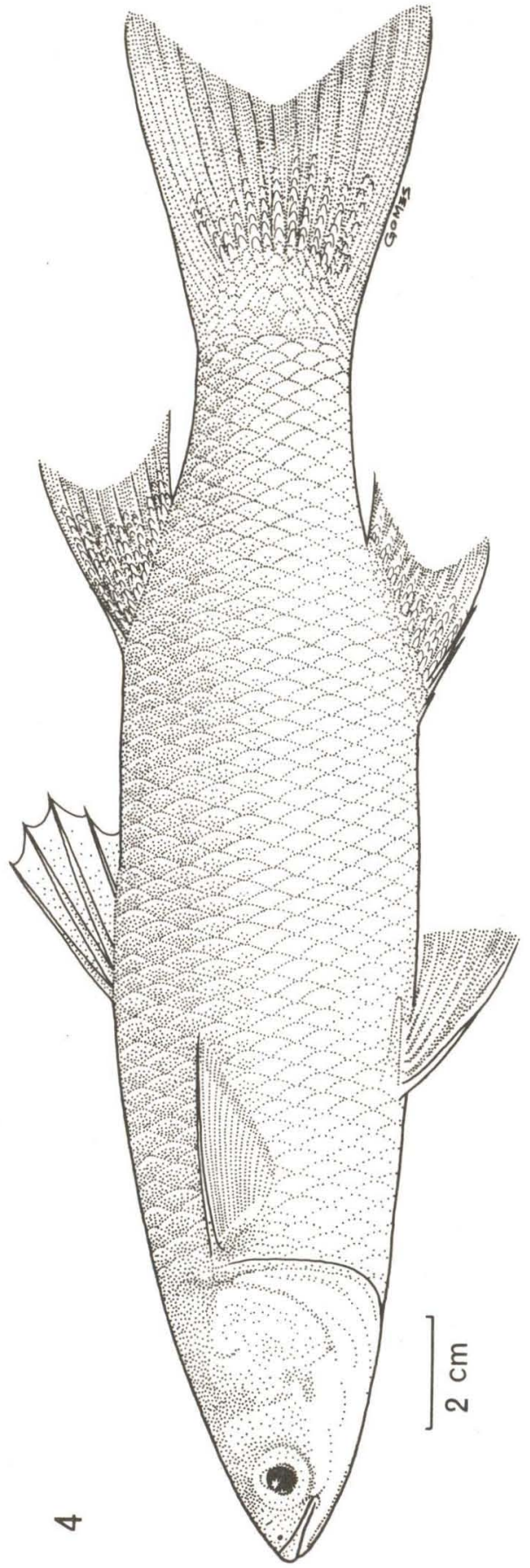

Fig. 4 - Mugil incilis, 27,5 cm. 


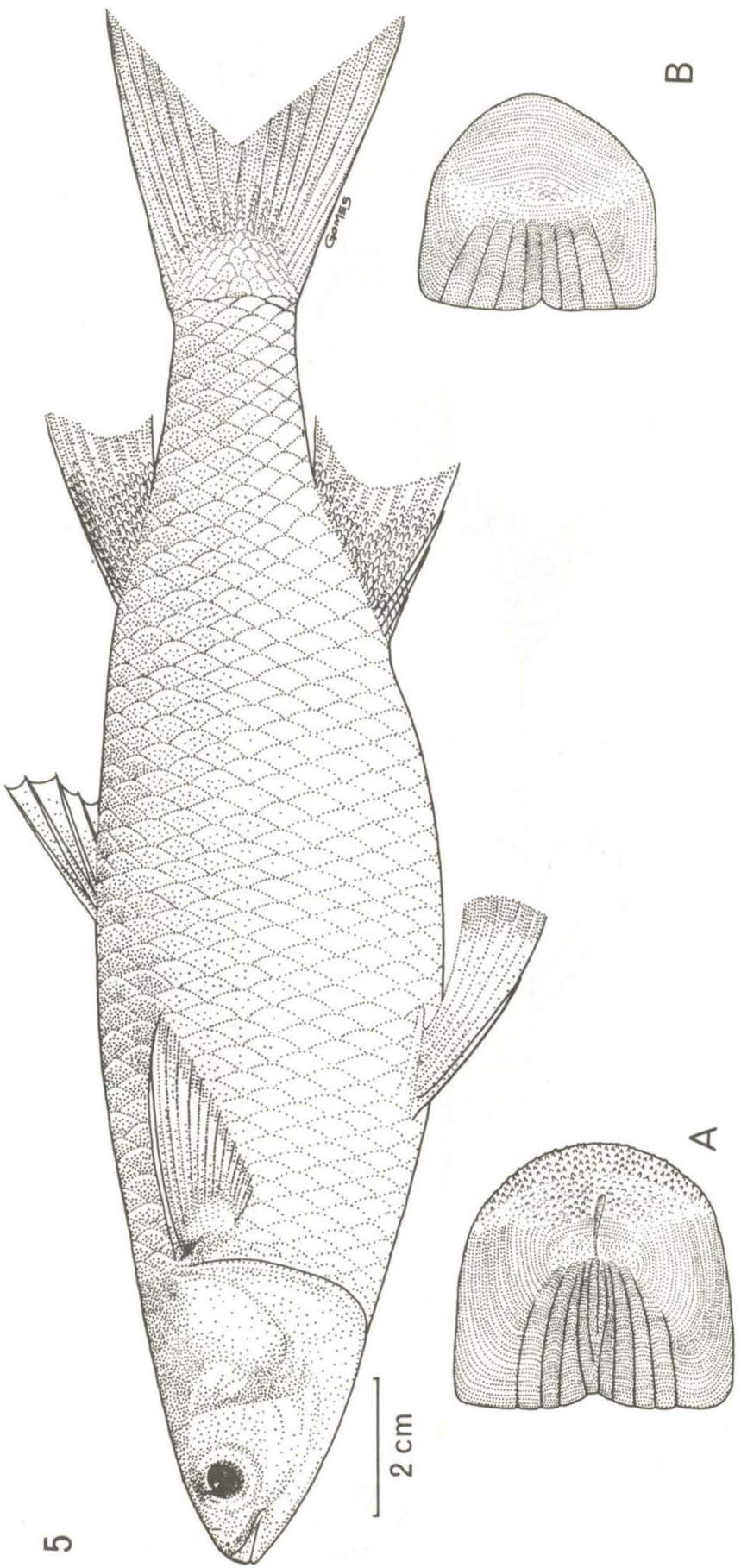

Fig. 5 - Mugil curema, 22,5 cm; A - estrutura de uma escama situada aproximadamente no meio da parte lateral esquerda do corpo; B - idem, situada na mesma posição em um exemplar jovem $(6,0 \mathrm{~cm})$. 


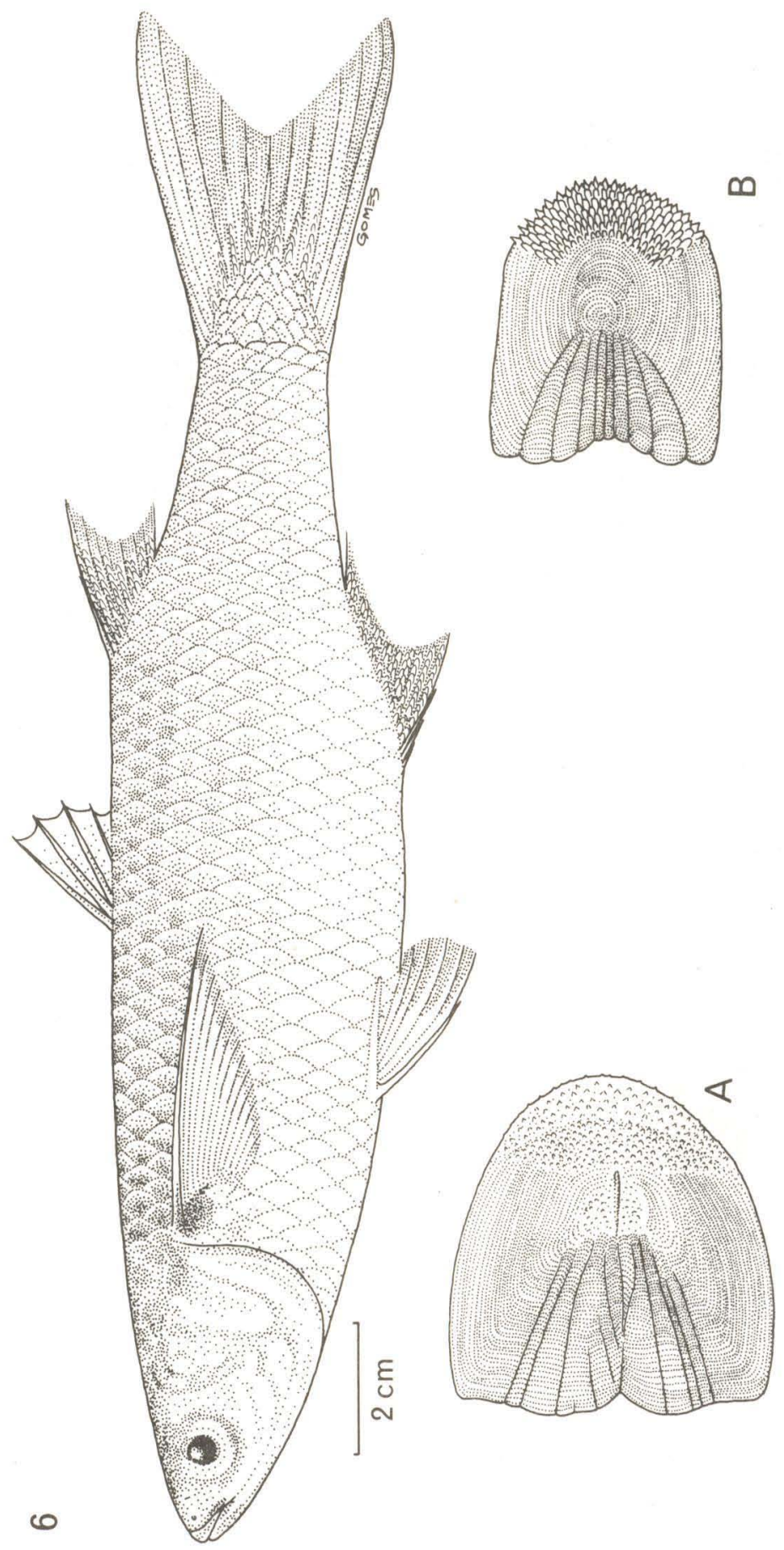

Fig. 6 - Mugil gaimardianus. A - estrutura de uma escama situada aproximadamente no meio da parte lateral esquerda do corpo; B - idem, situada na mesma posição em um exemplar jovem $(5,0 \mathrm{~cm})$. 

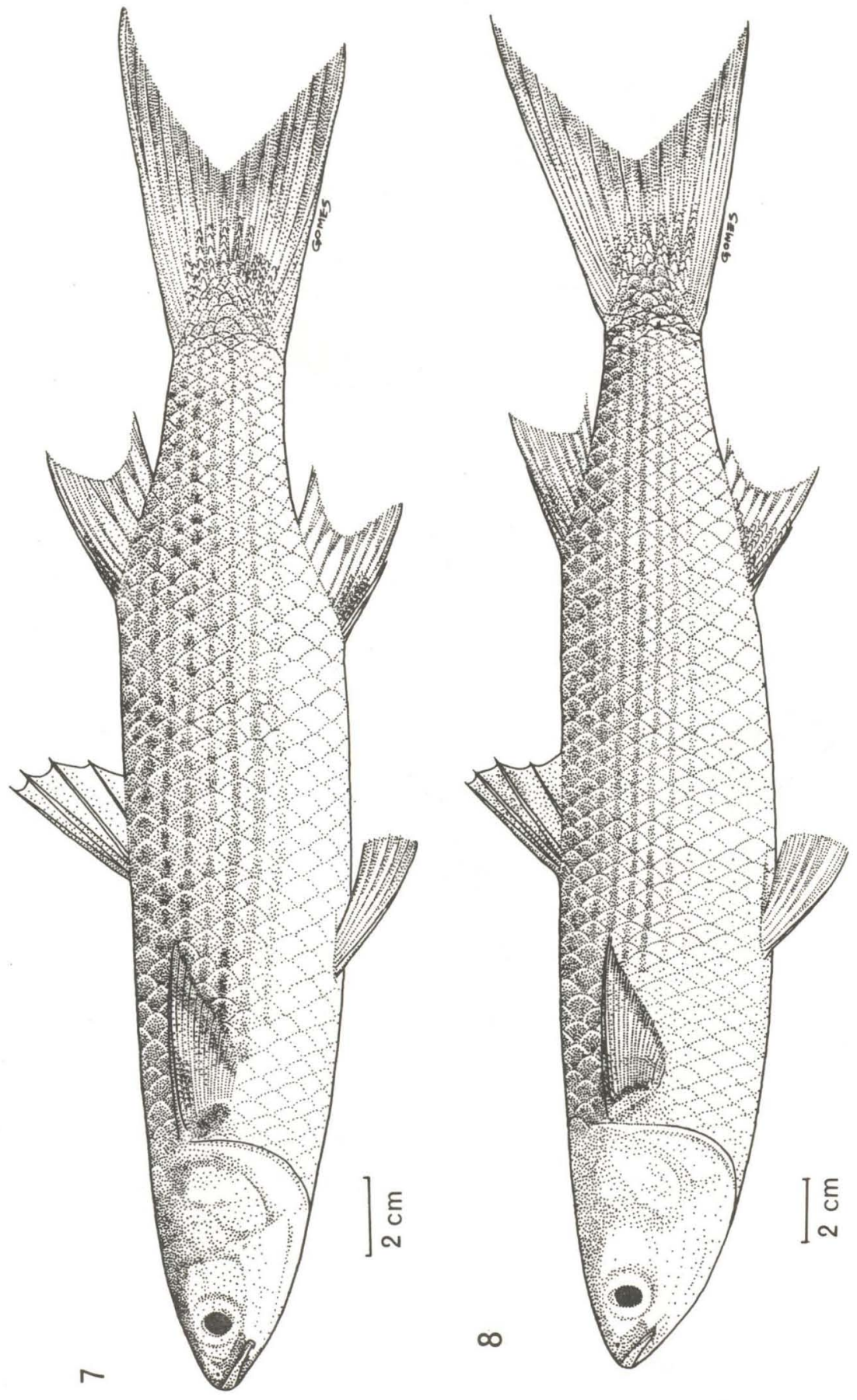

Fig. 7 - Mugil liza, 34,0 cm. Fig. 8 - Mugil platanus, $42,0 \mathrm{~cm}$. 